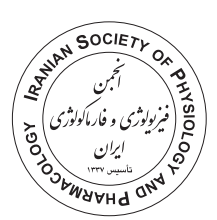

\title{
Time course study of ERK1/2 activity and cell viability in lipopolysaccharide challenged PC12 cells
}

Pegah Javadpour ${ }^{1,3 \#}$, Sahar Askari ${ }^{1,3 \#}$, Fateme Azizi ${ }^{2}$, Rasoul Ghasemi ${ }^{1,3^{*}}$ (iD

1. Department of Physiology, School of Medicine, Shahid Beheshti University of Medical Sciences, Tehran, Iran

2. School of advanced medical technologies, Tehran university of medical sciences, Tehran, Iran

3. Neurophysiology Research Center, Shahid Beheshti University of Medical Sciences, Tehran, Iran

\begin{abstract}
Introduction: Extracellular signal-regulated kinase 1 and 2 (ERK1/2) are important members of mitogen-activated protein kinases (MAPK), which are actively involved in the shaping of cellular responses to different stimuli; however, these responses are somehow contradicting. It is believed that time is a crucial factor in the determination of these effects. Therefore, the present work was designed to obtain a more vivid view about the effect of time on ERK activity and its relation to cell viability.

Methods: In the first step, we challenged cultured PC12 cells with different doses of lipopolysaccharides (LPS) for different time intervals $(3,6,24$ and 48h) and the cell viability was checked by MTT test. Thereafter, we cultured the cells in 6-well plates and treated them with the effective dose $(10 \mu \mathrm{g} / \mathrm{ml})$ for the abovementioned intervals and the level of ERK phosphorylation, as the active form, was assessed in the Western blotting analysis.

Results: The results showed that treating cells with $10 \mu \mathrm{g} / \mathrm{ml}$ LPS reduces cell viability after 48h. While being ineffective in shorter periods of time, ERK activity has a fluctuating trend, so that it reaches the highest level at $6 \mathrm{~h}$, thereafter it declines to the lowest level at $24 \mathrm{~h}$ and partially increases again at $48 \mathrm{~h}$.

Conclusion: These results imply that time is a determinant factor in the activity of ERK and single-point assessments may result in misinterpretation.
\end{abstract}

\section{Introduction}

Extracellular signal-regulated kinase $1(44 \mathrm{kDa})$ and 2 $(42 \mathrm{kDa})(\mathrm{ERK} 1 / 2)$ or briefly ERK are members of the mammalian family of mitogen-activated protein kinases (MAPKs). The activated form of ERKs is the phosphorylated form on tyrosine and threonine residues. Phosphorylation of ERKs can be triggered in response to different stimuli such as cytokines, chemokines, growth

\author{
Keywords: \\ Inflammation \\ Time factors \\ ERK1/ 2 MAPK \\ Lipopolysaccharides \\ PC12 cells
}

\footnotetext{
* Corresponding author: Rasoul Ghasemi, Rghasemi60@sbmu.ac.ir

\#Pegah Javadpour and Sahar Askari contributed equally to this work and should be considered as co-first authors.

Received 16 April 2020; Revised from 7 September 2020; Accepted 3 October 2020

Citation: Javadpour P, Askari S, Azizi F, Ghasemi R. Time course study of ERK1/2 activity and cell viability in lipopolysaccharide challenged PC12 cells. Physiol ogy and Pharmacology 2021; 25: 76-82. http://dx.doi.org/10.32598/ppj.25.1.50
}

factors and oxidative stress (Cheng et al., 2013). Once phosphorylated, ERKs are implicated in the regulation of cellular processes such as differentiation and proliferation, cell survival and/or apoptosis (Abbasnejad et al., 2019; Cheng et al., 2013). In order to accomplish these diverse effects, ERK isoforms participate in shaping the response of different signaling pathways, such as regulation of inflammatory responses (Sabio and Davis, 
2014). In this regard, the question, which may arise is how a signaling molecule could contribute to such diverse and even opposing effects. It seems that time is an important factor in revealing these effects (Abbasnejad et al., 2019; Stanciu et al., 2000). Accordingly, it has been demonstrated that ERK can be a survival factor for the cell when activated in short periods, but its activation in longer periods can lead to cellular death (Li et al., 2002). Considering these points and in order to expand our understanding about the role that time play in forming cellular responses, we aimed to assess time-dependency of ERK activity and its correlation with cell viability in 4 different time points (3, 6, 24 and 48h) after challenged with LPS.

\section{Material and methods}

\section{Chemicals}

Hanks' Balanced Salt (HBS, H2387) and LPS (L2880) were purchased from Sigma-Aldrich. Cell culture material including 3-(4,5-Dimethylthiazol-2-yl)-2,5-diphenyltetrazolium bromide (MTT), dimethyl sulfoxide (DMSO), complete Dulbecco's Modified Eagle's Medium (DMEM), fetal bovine serum (FBS) and penicillinstreptomycin (15140-122) were from Gibco. Antibodies against phospho-ERK antibody (Rabbit mAb \#4377), Total ERK antibody (Rabbit mAb \#4695), beta-actin antibody (Rabbit mAb \#4970) and secondary HRP-conjugated antibody (Anti-rabbit IgG, HRP-linked Antibody \#7074) were obtained from Cell Signaling Technology. Amersham ECL select ${ }^{\mathrm{TM}}$ (RPN2235) reagent kit was purchased from GE health care. Bovine serum albumin (BSA, 1120180100) and PVDF membrane (IPVH00010) were purchased from Millipore.

\section{PC12 culture}

PC12 cells were obtained from the Neuroscience Research Center, Shahid Beheshti University of Medical Sciences. The cells were cultured in complete DMEM medium (with 10\% FBS, 1\% antibiotic mixture comprising penicillin-streptomycin) in T25 flasks which were preserved at $37^{\circ} \mathrm{C}$ in a $5 \% \mathrm{CO} 2$ incubator at $37^{\circ} \mathrm{C}$ and $95 \%$ humidified atmosphere. The medium of the cells was exchanged every 2 days. For the experiments, equal numbers of PC12 cells were seeded in 96 or 6 well plates. The ethics committee of Shahid Beheshti University of Medical Sciences approved the experimental protocol (IR.SBMU.MSP.REC.1395.280).

\section{Cell viability assay}

In order to reach the toxic dose of LPS, cells were seeded in 96 well plates in DMEM containing 10\% FBS. One day later, the culture medium was replaced with $1 \%$ FBS and cells treated with various dosages of LPS $(500 \mathrm{ng} / \mathrm{ml}, 1,5$ and $10 \mu \mathrm{g} / \mathrm{ml})$ in the time courses of 3, 6, 24 and $48 \mathrm{~h}$ and cell viability was quantified by the colorimetric MTT assay. LPS (as a specific inducer for inflammation) was dissolved primarily in saline as a stock solution and then diluted in culture media to make final concentrations. At the end of treatment time, the cell culture medium was removed and changed with a DMEM media containing $0.5 \mathrm{mg} / \mathrm{ml}$ of MTT. Then, the cells were returned into the incubator $\left(37^{\circ} \mathrm{C}\right)$ for $4 \mathrm{~h}$, in this period, metabolically viable cells transform MTT into an insoluble formazan. Finally, the media was removed and the purple formazan crystals were dissolved in $100 \mu 1$ of DMSO and the absorbance of samples was measured at a wavelength of $570 \mathrm{~nm}$ with a microplate reader.

\section{Western blot assay}

Cells were lysed and homogenized in an ice-cold RIPA lysis buffer containing protease and phosphatase inhibitors. After being incubated on ice for $30 \mathrm{~min}$, the lysates were centrifuged at $13,000 \mathrm{rpm}$ for $30 \mathrm{~min}$ at $4^{\circ} \mathrm{C}$. Then whole protein concentrations of cells were measured by the Bradford method. In the next step, equal amounts of proteins were separated on $12 \%$ SDS-PAGE gel and transferred to PVDF membrane. Thereafter, the blots were blocked in 5\% BSA for $1 \mathrm{~h}$ at room temperature and then incubated with primary antibodies (P-ERK, T-ERK and beta-actin) overnight at $4{ }^{\circ} \mathrm{C}$. The membranes then were rinsed and probed with secondary antibody for $1.5 \mathrm{~h}$ at room temperature. In the next step, in order to reveal the immunoreactive bands, ECL was added to the blots. Finally, the quantitative value of bands were obtained by Image $\mathbf{J}$ software.

\section{Statistical analysis}

All data were expressed as mean \pm SEM. Results were analyzed by unpaired t-test and one-way ANOVA followed by Tukey's post-hoc test for multiple comparisons. $P<0.05$ was defined statistically significant. GraphPad Prism 6 Demo (GraphPad Software) program was used to data analysis. 


\section{Results}

In order to reach the effective dose of LPS, we determined the cell viability of PC12 cells by MTT assay. To accomplish this, cells were incubated with LPS (four different doses: $500 \mathrm{ng} / \mathrm{ml}, 1,5$ and $10 \mu \mathrm{g} / \mathrm{ml}$ ) for $48 \mathrm{~h}$. As depicted in Figure 1, analysis of cell viability after $48 \mathrm{~h}$ implied that incubating of the cells with LPS in all doses resulted in decreased cell viability in comparison to control $(\mathrm{F}(4,33)=33.87, P<0.0001)$. However, cell death is more severe in $10 \mu \mathrm{g} / \mathrm{ml}$ treated cells $(P<0.0001)$. More-

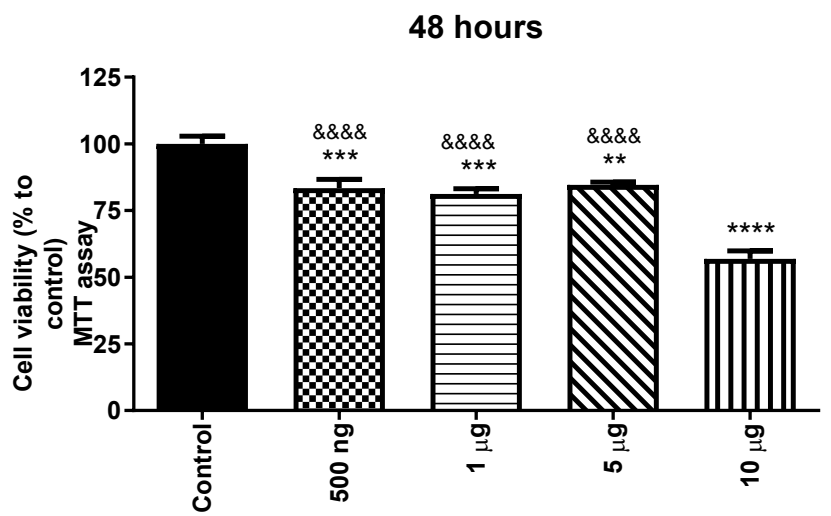

FIGURE 1. Dose dependent study of LPS on cell viability in PC12 cells after $48 \mathrm{~h}$. Data are represented as mean \pm SEM. ${ }^{* *} P<0.01$, ${ }^{* * *} P<0.001$ and ${ }^{* * * * *} P<0.0001$, represent the difference between control and other groups. ${ }^{\text {\&d\&\& }} P<0.0001$, represents the difference between $10 \mu \mathrm{g} / \mathrm{ml}$ and other groups.
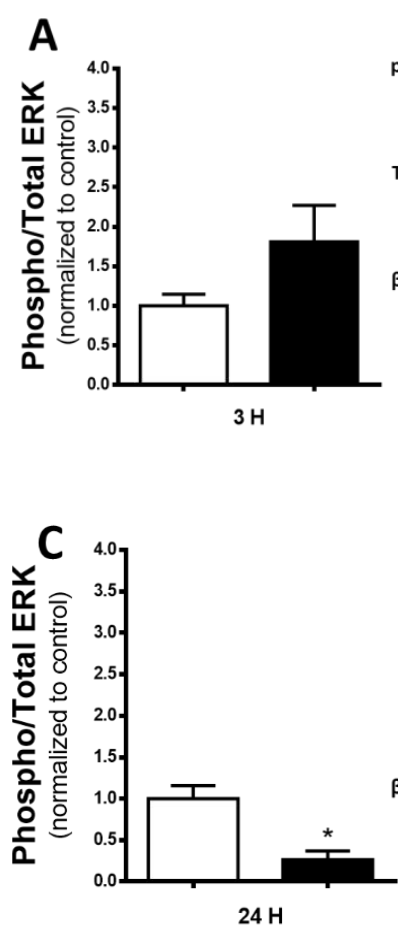
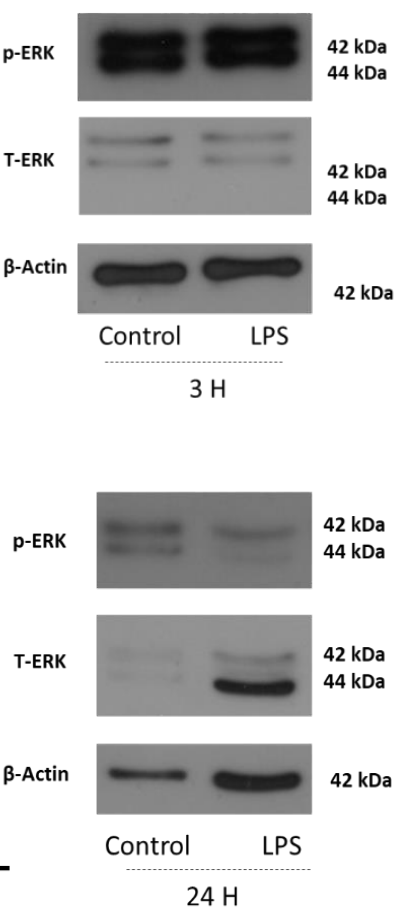

over, cells receiving $10 \mu \mathrm{g} / \mathrm{ml}$ LPS had significantly lower cell viability compared to $500 \mathrm{ng} / \mathrm{ml}, 1$ and $5 \mu \mathrm{g} / \mathrm{ml}$ LPS treated cells $(P<0.0001)$. Based on these results, we chose $10 \mu \mathrm{g} / \mathrm{ml}$ and analyzed its effect on cell viability in 4-time points (3, 6, 24 and 48h). It is evident in Figure 2 that, there were no significant changes between the control and LPS groups unless the $48 \mathrm{~h}$ group.

\section{The time-course study of ERK activity}

To evaluate the activity of ERK, phosphorylated and

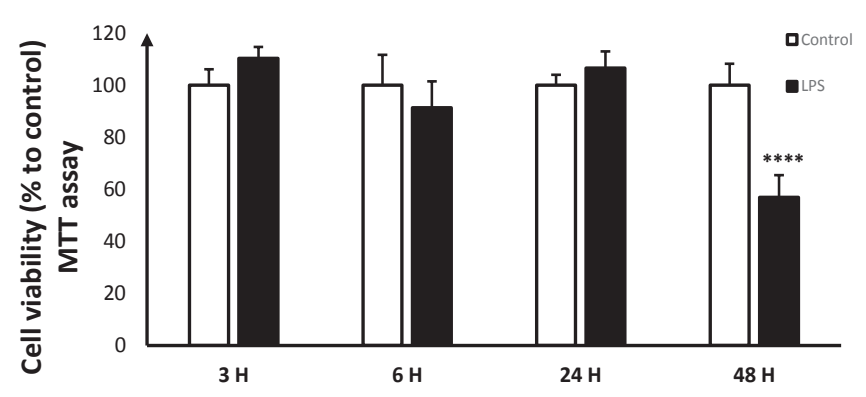

FIGURE 2. Time dependent study of $10 \mu \mathrm{g} / \mathrm{ml}$ LPS on cell viability in PC1 2 cells. Data are represented as mean \pm SEM. ${ }^{* * * *} P<0.0001$, represent the difference between control and other groups.
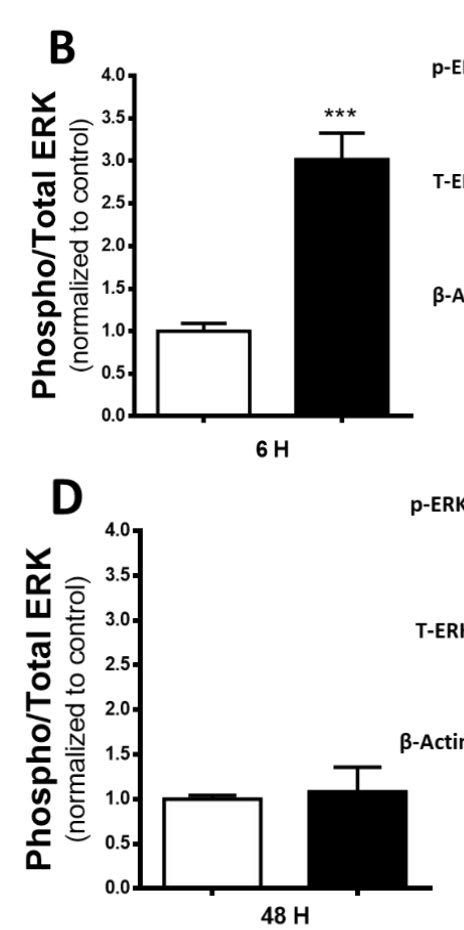
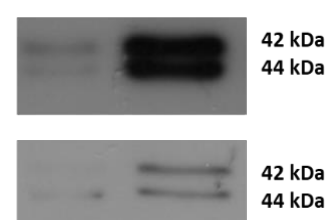

$\beta$-Actin

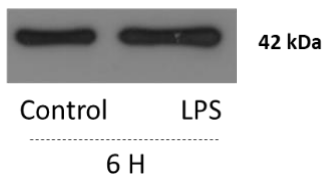

$6 \mathrm{H}$
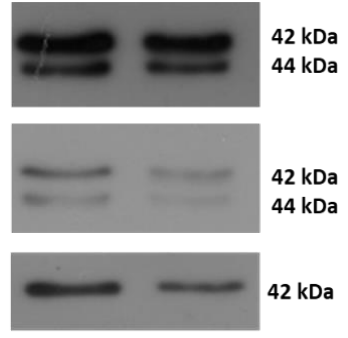

Control LPS

$48 \mathrm{H}$

FIGURE 3. Western blot analysis showing the time course effects of LPS on phosphorylated level of ERK; A, B, C and D are showing the comprative level of ERK phosphoryaltion 3, 6, 24 and $48 \mathrm{~h}$ after changing media and LPS treatment. Data are represented as mean \pm SEM. ${ }^{*} P<0.05$ and ${ }^{* * *} P<0.001$, represent the difference between control and LPS. Representative blot for each time is presented at right panel of each graph. 
total forms of this kinase were assessed by Western blotting. The bands of phospho-ERK (p-ERK) and total-ERK (T-ERK) were detected at 42 and $44 \mathrm{kDa}$. As showed in Figure 3, t-test analysis failed to significant difference between control and LPS after $3 \mathrm{~h}(\mathrm{t}=1.672$, $\mathrm{df}=4, P=0.1699)$. However, the result of analysis after $6 \mathrm{~h}$ showed a significant increase in ERK activity in LPS treating group ( $\mathrm{t}=6.248 \mathrm{df}=6, P=0.0008$ ). Interestingly, a significant decrease in ERK activity in the LPS group after $24 \mathrm{~h}$ was detected ( $\mathrm{t}=3.864 \mathrm{df}=4, P=0.0181$ ). Thereafter, ERK activity increased in the $48 \mathrm{~h}$ group and became insignificant with the control group $(\mathrm{t}=.3007$ $\mathrm{df}=6, P=0.7738)$.

\section{Discussion}

In this report, we aimed to investigate the correlation between duration of inflammation, cell viability and the activity of ERK. The upper range of this time course study was $48 \mathrm{~h}$, this time was the first time point in which the LPS treatment caused significant cell death when compared to the control group. Our results showed that ERK phosphorylation, as an indicator for its activity, fluctuate in a time dependent manner. Several studies have revealed the involvement of ERK in inflammation. ERK induces inflammatory cytokines such as interleukin (IL)- $1 \beta$, IL-8 and tumor necrosis factor- $\alpha$ (TNF- $\alpha$ ) (Kim, 2014; Kurosawa et al., 2000) and participate in various inflammatory disorders such as inflammatory osteolysis (Seo et al., 2010), cystic fibrosis (Verhaeghe et al., 2007), lung inflammatory diseases (Schuh and Pahl, 2009; Wuyts et al., 2003; Zhou et al., 2018) and arthritis (Thalhamer et al., 2008). In addition, it has been reported that inhibition of ERK phosphorylation can decrease neutrophil-dependent inflammation (Senger et al., 2017; Thalhamer et al., 2008). In contrast, Yong et al. have demonstrated that ERK inhibits IkappaB kinase (IKK) activity in endothelial cells, proving anti-inflammatory effects for this molecule (Maeng et al., 2006).

In the nervous system, ERK expression was reported in neurons, microglia, astrocytes and oligodendrocytes. Recently, it has been shown that ERK can control the release of many microglial proinflammatory mediators such as IL-1 $\beta$, IL-6, COX-2, iNOS and TNF- $\alpha$ (Jeong et al., 2019; Deng et al., 2012; Kim et al., 2014; Weinstein et al., 2009). Furthermore, a recent study demonstrated that microglial ERK is hyperphosphorylated in Alzheimer's disease. Accordingly, it was suggested that ERK plays a pivotal regulatory role in pro-inflammatory immune responses seen in this disease (Chen et al., 2019). As it was mentioned, ERK is also expressed in astrocytes and oligodendrocytes and plays critical roles in the inflammatory responses (Fields et al., 2013; Park et al., 2009; Parthasarathy and Philipp, 2014). As it was reviewed by Cruz and Cruz (2007), ERK pathway is also activated at the different neuronal levels, such as dorsal root ganglia, spinal cord and supraspinal centers and contributes to painful conditions that it could be a symptom of chronic inflammation. Consistently, ERK signaling in nociceptive spinal neurons might participate in inflammation mediated pain hypersensitivity (Zhang et al., 2014). Moreover, there are numerous studies that focus on the importance of pharmaceutical therapies to diminish neuroinflammation in CNS disorders by suppressing the ERK pathway (Jeong et al., 2019; Lim et al., 2019; Shao et al., 2013; Wang et al., 2010; Xia et al., 2015; Zhao et al., 2013). On the other hand, it has been reported that inhibition of microglial ERK attenuates the anti-inflammatory effects of anti-malarial agent, artesunate. Accordingly, it is suggested that ERK pathway might be required for anti-neuroinflammatory responses (Lee et al., 2012).

Supporting this conclusion, a large body of evidence have reported that time is a determinant factor for the activity of signaling molecules (Abbasnejad et al., 2019; Valledor et al., 2000). In accordance, Valledor et al. (2000) showed that peak time of ERK activity would determine how macrophages respond to proliferative or activating stimulants. Furthermore, our previous work on the effect of high-fat diet consumption on hippocampal MAPK signaling pathway, clearly demonstrated that JNK, P38 and ERK have a fluctuating pattern of activities when examined at different intervals after HFD consumption (Abbasnejad et al., 2019). Consistent with our results, a cell culture study also showed time dependency of ERK activity; however in shorter periods of time. This study showed that incubating of HP1 cells with LPS, leads to activation of the ERK pathway after $60 \mathrm{~min}$, co-treatment of these LPS-stimulated cells with minocycline increases ERK activity at $30 \mathrm{~min}$ but decayed after $60 \mathrm{~min}$. By this mechanism, it induced early suppression of induced chemokines and cytokines (Sun et al., 2015). Moreover, induction of inflammation with calcitonin gene-related peptides also resulted in a time-dependent increase in ERK phosphorylation pat- 
tern up to $1 \mathrm{~h}$ (Permpoonputtana et al., 2016). In addition, the increased ERK activity during the first hours of inflammation was also confirmed in a traumatic injury model. In this study, a robust rise in ERK phosphorylation level at $10 \mathrm{~h}$ post-injury followed by a decrease after $24 \mathrm{~h}$ were reported. The results also showed a rise in IL10 protein level as a stimulatory factor for ERK activity at first hours and increased mitogen-activated protein kinase phosphatase- 1 and phospho protein phosphatase 2A level as inhibitory factors for ERK activity from 24h (Szelenyi and Urso, 2012). In addition, an immunohistochemistry analysis for expression of p-ERK in the neurons of the superficial dorsal horn after ipsilateral spinal cord (L5) ligation indicated ERK activity peaked at $10 \mathrm{~min}$ after the injury and had a reducing trend until $6 \mathrm{~h}$ (however, at this time the number of p-ERK positive neurons is still higher than the control group). Although, in contrast to our results, this elevated activity was present in more than 3 weeks (Zhuang et al., 2005). Moreover, in a Freund's adjuvant (CFA) injection induced acute peripheral inflammation model, Zhang and colleagues (2014), showed that p-ERK expression level in the spinal cord dorsal horn started to increase at $2 \mathrm{~h}$, reached to maximum level after $24 \mathrm{~h}$ and this increased level remained high 7days after induction of inflammation. It is noteworthy to mention that LPS treatment was done in a lowered serum media (10\% vs $1 \%$ FBS). Therefore, the same lowering of serum was also done for control cells and as a result, we had different control groups for different time intervals, (having the same duration of serum deprivation as corresponding LPS group) and results of each time point was compared to its own control group. This could explain why, in our experiment, control cells also showed some variation in ERK activity when compared with other time points.

\section{Conclusion}

Collectively, our results clearly showed that before judgment about the activity level of a molecule such as ERK, we should consider this point that, in which time point the assessment was done? If we couldn't detect any changes in the activity level of a molecule in a particular time point, it doesn't necessarily mean that a molecule is not responsible at all. In fact, activation of each element in a signaling pathway could vary in a time dependent manner.

\section{Acknowledgment}

The authors are thankful to neuroscience research center and neurophysiology research center Shahid Beheshti University of Medical science for supporting this work.

\section{Conflicts of interest}

The authors declare that they have no conflict of interests.

\section{References}

Abbasnejad Z, Nasseri B, Zardooz H, Ghasemi R. Timecourse study of high fat diet induced alterations in spatial memory, hippocampal JNK, P38, ERK and Akt activity. Metab Brain Dis 2019; 34: 659-73. https://doi.org/10.1007/ s11011-018-0369-1

Chen MJ, Ramesha S, Weinstock LD, Gao T, Ping L, Xiao $\mathrm{H}$, et al. Microglial ERK signaling is a critical regulator of pro-inflammatory immune responses in Alzheimer's disease. bioRxiv 2019; 798215. https://doi. org/10.1101/798215

Cheng P, Alberts I, Li X. The role of ERK1/2 in the regulation of proliferation and differentiation of astrocytes in developing brain. Int J Dev Neurosci 2013; 31: 783-9. https:// doi.org/10.1016/j.ijdevneu.2013.09.008

Cruz CD, Cruz F. The ERK 1 and 2 pathway in the nervous system: from basic aspects to possible clinical applications in pain and visceral dysfunction. Curr Neuropharmacol 2007; 5:244-52.https://doi.org/10.2174/157015907782793630

Deng Z, Sui G, Rosa PM, Zhao W. Radiation-induced c-Jun activation depends on MEK1-ERK1/2 signaling pathway in microglial cells. PLoS One 2012; 7: e36739. https://doi. org/10.1371/journal.pone.0036739

Fields J, Cisneros IE, Borgmann K, Ghorpade A. Extracellular regulated kinase $1 / 2$ signaling is a critical regulator of interleukin-1 $\beta$-mediated astrocyte tissue inhibitor of metalloproteinase-1 expression. PLoS One 2013; 8: e56891. https://doi.org/10.1371/journal.pone.0056891

Jeong YH, Li W, Go Y, Oh YC. Atractylodis rhizoma alba attenuates neuroinflammation in BV2 microglia upon LPS stimulation by inducing HO-1 activity and inhibiting NFкB and MAPK. Int J Mol Sci 2019; 20: 4015. https://doi. org/10.3390/ijms20164015

Kim HK. Role of ERK/MAPK signalling pathway in anti-inflammatory effects of Ecklonia cava in activated human mast cell line-1 cells. Asian Pac J Trop Med 2014; 7: 7038. https://doi.org/10.1016/S1995-7645(14)60120-6 
Kim S, Lee MS, Lee B, Gwon WG, Joung EJ, Yoon NY, et al. Anti-inflammatory effects of sargachromenol-rich ethanolic extract of Myagropsis myagroides on lipopolysaccharide-stimulated BV-2 cells. BMC Complement Altern Med 2014; 14: 1-12. https://doi.org/10.1186/1472-6882-14-231

Kurosawa M, Numazawa S, Tani Y, Yoshida T. ERK signaling mediates the induction of inflammatory cytokines by bufalin in human monocytic cells. Am J Physiol Cell Physiol 2000; 278: C500-8. https://doi.org/10.1152/ajpcell.2000.278.3.C500

Lee IS, Ryu DK, Lim J, Cho S, Kang BY, Choi HJ. Artesunate activates Nrf2 pathway-driven anti-inflammatory potential through ERK signaling in microglial BV2 cells. Neurosci lett 2012; 509: 17-21. https://doi.org/10.1016/j. neulet.2011.12.034

Li F, Omori N, Sato K, Jin G, Nagano I, Manabe Y, et al. Coordinate expression of survival p-ERK and proapoptotic cytochrome $\mathrm{c}$ signals in rat brain neurons after transient MCAO. Brain Res 2002; 958: 83-8. https://doi. org/10.1016/S0006-8993(02)03465-0

Lim HS, Kim YJ, Kim BY, Jeong SJ. Bakuchiol suppresses inflammatory responses via the downregulation of the $\mathrm{p} 38$ MAPK/ERK signaling pathway. Int J Mol Sci 2019; 20: 3574. https://doi.org/10.3390/ijms20143574

Maeng YS, Min JK, Kim JH, Yamagishi A, Mochizuki N, Kwon JY, et al. ERK is an anti-inflammatory signal that suppresses expression of NF-kappaB-dependent inflammatory genes by inhibiting IKK activity in endothelial cells. Cell Signal 2006; 18: 994-1005. https://doi.org/10.1016/j. cellsig.2005.08.007

Park GH, Jeon SJ, Ryu JR, Choi MS, Han SH, Yang SI, et al. Essential role of mitogen-activated protein kinase pathways in protease activated receptor 2-mediated nitric-oxide production from rat primary astrocytes. Nitric Oxide 2009; 21: 110-9. https://doi.org/10.1016/j.niox.2009.05.007

Parthasarathy G, Philipp MT. The MEK/ERK pathway is the primary conduit for Borrelia burgdorferi-induced inflammation and P53-mediated apoptosis in oligodendrocytes. Apoptosis 2014; 19: 76-89. https://doi.org/10.1007/ s 10495-013-0913-8

Permpoonputtana K, Porter JE, Govitrapong P. Calcitonin gene-related peptide mediates an inflammatory response in Schwann cells via cAMP-dependent ERK signaling cascade. Life Sci 2016; 144: 19-25. https://doi.org/10.1016/j. 1fs.2015.11.015

Sabio G, Davis RJ. TNF and MAP kinase signalling pathways. Semin Immunol 2014; 26: 237-245. https://doi. org/10.1016/j.smim.2014.02.009

Schuh K, Pahl A. Inhibition of the MAP kinase ERK protects from lipopolysaccharide-induced lung injury. Biochem Pharmacol 2009; 77: 1827-34. https://doi.org/10.1016/j. bcp.2009.03.012

Senger K, Pham VC, Varfolomeev E, Hackney JA, Corzo CA, Collier J, et al. The kinase TPL2 activates ERK and p38 signaling to promote neutrophilic inflammation. Sci Signal 2017; 10. https://doi.org/10.1126/scisignal.aah4273

Seo SW, Lee D, Minematsu H, Kim AD, Shin M, Cho SK, et al. Targeting extracellular signal-regulated kinase (ERK) signaling has therapeutic implications for inflammatory osteolysis. Bone 2010; 46: 695-702. https://doi.org/10.1016/j. bone.2009.10.032

Shao J, Liu T, Xie QR, Zhang T, Yu H, Wang B, et al. Adjudin attenuates lipopolysaccharide (LPS)-and ischemia-induced microglial activation. J Neuroimmunol 2013; 254: 83-90. https://doi.org/10.1016/j.jneuroim.2012.09.012

Stanciu M, Wang Y, Kentor R, Burke N, Watkins S, Kress $\mathrm{G}$, et al. Persistent activation of ERK contributes to glutamate-induced oxidative toxicity in a neuronal cell line and primary cortical neuron cultures. J Biol Chem 2000; 275: 12200-6. https://doi.org/10.1074/jbc.275.16.12200

Sun J, Shigemi H, Tanaka Y, Yamauchi T, Ueda T, Iwasaki H. Tetracyclines downregulate the production of LPS-induced cytokines and chemokines in THP-1 cells via ERK, p38, and nuclear factor-kappaB signaling pathways. Biochem Biophys Rep 2015; 4: 397-404. https://doi.org/10.1016/j. bbrep.2015.11.003

Szelenyi ER, Urso ML. Time-course analysis of injured skeletal muscle suggests a critical involvement of ERK1/2 signaling in the acute inflammatory response. Muscle Nerve 2012; 45: 552-61. https://doi.org/10.1002/mus.22323

Thalhamer T, McGrath M, Harnett M. MAPKs and their relevance to arthritis and inflammation. Rheumatology 2008; 47: 409-14. https://doi.org/10.1093/rheumatology/kem297

Valledor AF, Comalada M, Xaus J, Celada A. The differential time-course of extracellular-regulated kinase activity correlates with the macrophage response toward proliferation or activation. J Biol Chem 2000; 275: 7403-9. https://doi. org/10.1074/jbc.275.10.7403

Verhaeghe C, Remouchamps C, Hennuy B, Vanderplasschen A, Chariot A, Tabruyn SP, et al. Role of IKK and ERK pathways in intrinsic inflammation of cystic fibrosis airways. Biochem Pharmacol 2007; 73: 1982-94. https://doi. org/10.1016/j.bcp.2007.03.019

Wang YJ, Zheng YL, Lu J, Chen GQ, Wang XH, Feng J, et 
al. Purple sweet potato color suppresses lipopolysaccharide-induced acute inflammatory response in mouse brain. Neurochem Int 2010; 56: 424-30. https://doi.org/10.1016/j. neuint.2009.11.016

Weinstein JR, Zhang M, Kutlubaev M, Lee R, Bishop C, Andersen H, et al. Thrombin-induced regulation of CD95(Fas) expression in the N9 microglial cell line: evidence for involvement of proteinase-activated receptor(1) and extracellular signal-regulated kinase 1/2. Neurochem Res 2009; 34: 445-52. https://doi.org/10.1007/s11064-008-9803-9

Wuyts WA, Vanaudenaerde BM, Dupont LJ, Demedts MG, Verleden GM. Involvement of p38 MAPK, JNK, p42/ p44 ERK and NF-kappaB in IL-1beta-induced chemokine release in human airway smooth muscle cells. Respir Med 2003; 97: 811-7. https://doi.org/10.1016/S09546111(03)00036-2

Xia Q, Hu Q, Wang H, Yang H, Gao F, Ren H, et al. Induction of COX-2-PGE2 synthesis by activation of the MAPK/ ERK pathway contributes to neuronal death triggered by TDP-43-depleted microglia. Cell Death Dis 2015; 6: e1702. https://doi.org/10.1038/cddis.2015.69

Zhang X, Zhang H, Shao H, Xue Q, Yu B. ERK MAP kinase activation in spinal cord regulates phosphorylation of Cdk5 at serine 159 and contributes to peripheral inflammation induced pain/hypersensitivity. PLoS One 2014; 9: e87788. https://doi.org/10.1371/journal.pone.0087788

Zhao H, Wang SL, Qian L, Jin JL, Li H, Xu Y, et al. Diammonium glycyrrhizinate attenuates $A \beta 1-42$-induced neuroinflammation and regulates MAPK and NF- $\kappa$ B pathways in vitro and in vivo. CNS Neurosci Ther 2013; 19: 117-24. https://doi.org/10.1111/cns.12043

Zhou QL, Wang TY, Li M, Shang YX. Alleviating airway inflammation by inhibiting ERK-NF- $\kappa$ B signaling pathway by blocking Kv1. 3 channels. Int Immunopharmacol 2018; 63: 110-8. https://doi.org/10.1016/j.intimp.2018.07.009

Zhuang ZY, Gerner P, Woolf CJ, Ji RR. ERK is sequentially activated in neurons, microglia, and astrocytes by spinal nerve ligation and contributes to mechanical allodynia in this neuropathic pain model. Pain 2005; 114: 149-59. https://doi.org/10.1016/j.pain.2004.12.022 